\title{
The relationship between attachment, the self- conscious emotions of shame and guilt \& problem behavior in adolescents
}

\author{
R.C.E.T.G. Houtackers \\ Maastricht University \\ rcetg.houtackers@student.maastrichtuniversity.nl
}

\begin{abstract}
A cross-sectional study was conducted to explore the relationship between attachment, the self-conscious emotions of shame and guilt, and problem behavior in adolescents. The study was performed in clinical adolescents aged 13-18 years $(N=31)$ who had been in contact with the Child Care and Protection Agency. They completed questionnaires measuring shame and guilt, the quality of the attachment relationship and the extent of problem behavior. Results demonstrated that communication, a positive dimension of attachment, was positively associated with various forms of shame and guilt. It was found that trust in parents and peers was associated with a higher extent of conduct problems and hyperactivity. Results also revealed that guilt (unambiguous) was positively correlated with pro-social behavior. Shame (ambiguous) was positively associated with emotional symptoms. Regression analysis showed that both age and gender accounted for an independent and significant proportion of the variance in children's problem behavior. Altogether, these results fit with the theory that attachment (in)security is involved in the extent of problem behavior and people's proneness to experience self-conscious emotions.
\end{abstract}

Keywords

Attachment, self-conscious emotions, problem behavior, adolescents.

\section{Introduction}

Problem behavior in adolescents is very common. In fact, almost every day when we open the news we see examples of underage people committing an offense without any sense of shame or guilt. For the victims and those left behind the lack of these kind of selfconscious emotions is very confrontational. It is interesting to observe the lack of self- 
conscious emotions, especially shame and guilt. A big finger points to the way of parenting (Aunola \& Nurmi, 2005; Soenens, Vansteenkiste, Luyckx \& Goossens, 2006). Parenting, however, is a rather broad concept. An important element in parenting is the attachment between parent and child. The major development challenge for children aged from birth to two years is to establish a secure attachment relationship with one or more adults (Meij, 2011). Securely attached children see their caregiver as a secure base from which they can explore the environment. During this period, early in life, the foundations for trust in others, confidence in their own abilities and the development of the personality will be laid (Cooper, Shaver \& Collins, 1998). Therefor, events very early in life influence future behavior of an individual.

A powerful theory in the field of attachment and parent-child interaction is the attachment theory of Bowlby (1969). The attachment theory suggests that children attach themselves to the primary caregiver, even when care is poor. According to Bowlby (1969) continues attachment behavior throughout life. Early attachment experiences are stored in the personality as internal working models, which arise from secure or insecure attachment. These cognitive models reflect the cognitions that a child has developed about themself, others and the attachment relationship as a whole. Further experiences in life regarding relationships are assessed from these internal working models (Ammaniti, Van IJzendoorn, Speranza \& Tambelli, 2010; Zaal, Boerhave \& Koster, 2009). If early childhood attachment is disrupted and is not safe, it will have a significant, negative impact on social life in childhood, adolescence and even adulthood (Sroufe, 2005). A disruption in the attachment relationship is associated with various forms of psychopathology and a disruption of selfconscious emotions (Erickson, Sroufe \& Egeland, 1985; Muris et al., 2014; Zegers, Schuengel, Van IJzendoorn \& Janssens, 2008).

Self-conscious emotions, such as shame and guilt, play a central role in motivating and regulating behavior, feelings and thoughts (Tracy \& Robins, 2004). These emotions motivate individuals to work harder in performance and function domains and regulate interpersonal behavior by getting people to behave in morally and socially appropriate ways in social interactions and intimate relations (Leith, \& Baumeister, 1998; Muris \& Meesters, 2014). Shame is the product of a complex set of cognitive activities: the evaluation of actions of an individual in relation to standards, rules and goals, and an overall evaluation of himself (Lewis, 2008). Shame is not caused by a specific situation, but by the personal interpretation of an event. The individual is anxious to be rejected and sees itself as a whole failure ("How could I do that?"). Guilt occurs when a person 
evaluates his or her behavior as a failure. In that case, an individual focuses on the specifics of himself, or the actions themselves that lead to a failure ("How could I do that"). This contrasts with shame, which focuses on the totality of someone. In conclusion, shame refers to the reporting of itself as subject and object, while in the case of guilt the person himself is distinguished from the object. Because of this difference, the emotion in the case of guilt is less intense.

The relationship between attachment and self-conscious emotions, attachment and problem behavior and between self-conscious emotions and problem behavior has been demonstrated several times but evidence for an association between these three variables combined is limited. With this in mind, the present study was designed to investigate the relationship between these three variables combined in adolescents. The study was conducted on the basis of a cross-sectional design wherein the results of the participants were measured once. A group of young people $(N=31)$ who have been in contact with the Child Care and Protection Agency filled out some questionnaires. These questionnaires focused on the quality of attachment, the tendency to experience the self-conscious emotions of shame and guilt, and the extent of psychological problems. Based on theory and previous studies it was hypothesized that (1) children who are insecurely attached exhibit lower levels of self-conscious emotions. In addition, it was expected that (2) insecure attachment, just as a disruption of self-conscious emotions, was associated with problem behavior. Furthermore, it was expected that (3) attachment and self-conscious emotions were independent predictors for the overall level of problem behavior.

\section{Material and methods}

\section{Participants and procedure}

The present sample consisted of 31 youths ( 22 boys and 9 girls) recruited from the Child Care and Protection Agency in Maastricht and Roermond. The mean age of the youths was 15.7 years $(S D=1.21$; range $=13-18$ years $)$. The most common reason for contact with police/ justice was theft (32.3\%), followed by assault (25.8\%). To be included in the study, the participants had to meet the following criteria: (1) the mother tongue was Dutch, (2) they were aged between 12-18 years, (3) they had committed at least one mild or serious crime over the past two years, and (4) they were living with at least one parent or guardian.

Adolescents and parents/guardians received an information letter about the study, which also invited them to participate. After both adolescents and parents/guardians had given their informed consent, the participants were kindly asked to complete a set of questionnaires. 


\section{Measures}

The study was part of a more extensive study, which included five questionnaires, namely the SCEMAS, EMBU-K, SDO, IPPA and TRA-A. The study involved the relationship between attachment (IPPA), parenting styles (EMBU-K), self-conscious emotions (SCEMAS) and the behavior of young people (SDO and TRA-A). Given the research question and interest, the present study was only based on three of the above-mentioned questionnaires, namely the SCEMAS, IPPA and the SDQ.

The Self-Conscious Emotions, Maladaptive and Adaptive Scales (SCEMAS), originally developed by Stegge and Ferguson (1994), is an instrument to measure children's proneness to experience self-conscious emotions. The questionnaire focuses on the selfconscious emotions of guilt, shame, ruminative guilt, externalization, anger and pride. However, in the current study was only focused on the self-conscious emotions of shame and (ruminative) guilt. The SCEMAS includes eight non-ambiguous situations derived from the Child-Child and Attribution Reaction Survey (C-CARS; Stegge \& Feguson, 1990). In these eight non-ambiguous situations violates a protagonist moral standards or failed in front of others. Stegge and Ferguson (1994) added five ambiguous situations where another person is harmed but the protagonist is not directly responsible. It also provides a positive result for the protagonist himself.

The Inventory of Parent and Peer Attachment (IPPA) was used to assess the quality of the attachment relationship of young people with parents and peers (Armsden \& Greenberg, 1987). The IPPA was designed to measure the specific working models of attachment by going into all the positive cognitive/affective experiences of good communication and confidence in the availability and responsiveness of attachment figures, as well as the negative cognitive/affective experiences of hopelessness and/or anger in consequence of non-responsive attachment figures (Armsden \& Greenberg, 1987). The questionnaire consists a parent scale (IPPA-PA) and a peer scale (IPPA PE). Both scales contain statements related to three areas of the attachment quality: trust, communication and alienation (Armsden \& Greenberg, 1987).

The Strengths and Difficulties Questionnaire (SDO) is a short questionnaire, which covers both the main areas of child psychopathology (emotional symptoms, conduct problems, hyperactivity and peer problems) and personal strengths (pro-social behavior) (Goodman, 1997; Muris, Meesters \& van den Berg, 2003). This questionnaire was used in the present study to determine problem behavior of youth. 


\section{Results}

\section{Correlations between attachment and self-conscious emotions}

Bivariate correlation analysis did not entirely revealed the expected pattern of positive correlations between insecure attachment and lower levels of self-conscious emotions. A number of significant positive correlations were found for the subscale communication. IPPA-PA communication was significantly positive correlated with SCEMAS guilt $(r=0.37$, $p<0.05)$, SCEMAS shame $(r=0.48, p<0.01)$, and SCEMAS shame non-ambiguous $(r=0,47$, $p<0.05)$. In addition, a significant correlation was found between IPPA-PE communication and SCEMAS guilt non-ambiguous $(r=0.37, p<0.05)$, and SCEMAS shame non-ambiguous $(r=0.42, p<0.05)$. These positive correlations indicated that one of the positive dimensions of attachment, communication, positively correlated with different forms of shame and guilt. This finding suggested that secure attachment was associated with a higher propensity to experience guilt, shame and shame in non-ambiguous situations. However, it was striking that IPPA-PE alienation was also significantly positively correlated with SCEMAS guilt ambiguous $(r=0.41, p<0.05)$. Alienation is seen as the negative dimension of attachment. A high score on alienation, which is associated with insecure attachment, was thus associated with more feelings of guilt. The remaining correlations were not significant.

\section{Correlations between attachment and problem behavior}

Insecure attachment was not significantly correlated with the total extent of difficulties. However, there was a significant correlation between IPPA-PA trust and SDQ conduct problems $(r=-0.53, p<0.01)$, IPPA-PE trust and SDO hyperactivity $(r=0.39, p<0.05)$, and SDQ peer problems $(r=-0.43, p<0.05)$. These correlations showed varying relationships between attachment and self-conscious emotions. Confidence in parents was negatively correlated with conduct problems, which means a better quality of the attachment relationship was associated with less conduct problems. A negative correlation was also found for trust in peers and problems with peers. As a result, a higher degree of secure attachment was associated with fewer problems with peers. Trust in peers on the other hand was positively correlated with hyperactivity. This relationship indicated a higher degree of secure attachment associated with higher levels of hyperactivity. Further, a negative correlation was found between IPPA-PA alienation and SDO hyperactivity $(r=$ $-0.42, p<0.05)$. More alienation toward parents was accompanied by less hyperactivity. The remaining correlations were not significant. 


\section{Correlations between self-conscious emotions and problem behavior}

Between self-conscious emotions and the overall level of difficulties were also no significant correlations found. The various subscales showed only two significant correlations. SCEMAS guilt non-ambiguous and SDQ pro-social behavior correlated positive with each other $(r=0.42, p<0.05)$, as well as SCEMAS shame ambiguous and SDQ emotional symptoms $(r=0.57, p<0.01)$. These positive correlations suggested that the experience of guilt in non-ambiguous situations and shame in ambiguous situations was accompanied with respectively pro-social behavior and emotional symptoms. All other correlations were not significant.

Attachment and self-conscious emotions: unique predictors of problem behavior? A regression analysis that contained all relevant variables was performed to test whether attachment and self-conscious emotion were significant independent predictors of problem behavior. The regression analysis did not show the desired effect; attachment and self-conscious emotions were no significant predictors of problem behavior [ $F$ $(16.8)=2.94, p=0.06]$. This suggested that the total extent of difficulties could not be predicted by the quality of the attachment relationship and the tendency to experience self-conscious emotions. Age and gender, on the other hand, were significant predictors of problem behavior $[\mathrm{F}(2,22)=8.85, p=0.002]$. The regression analysis showed that the increasing age was associated with a decrease in the overall extent of difficulties ( $\beta=$ $-0.52, p=0.004)$. In addition, it was found that girls experience a higher degree of overall problems in comparison with boys $(\beta=0.49, p=0.005)$.

\section{Discussion/Conclusion}

The present study examined the relationship between attachment, the self-conscious emotions of shame and guilt and problem behavior in a small sample of adolescents aged 13-18 years. The main results of the study can be classified as follows. First, communication with parents was positively associated with guilt, shame and shame in non-ambiguous situations. Communication with peers also correlated positive with guilt and shame, both in non-ambiguous situations. Alienation from peers however was positively related to feelings of guilt in ambiguous situations. Second, the results showed trust in parents has a negative correlation with conduct problems. Trust in peers was positively linked with hyperactivity, but negative with peer problems. Furthermore, parental alienation correlated negative with hyperactivity. Third, a positive association was found between pro-social behavior and guilt in non-ambiguous situations. Another positive correlation was found between emotional symptoms and shame in ambiguous situations. Fourth and 
finally, the present data seem to indicate that attachment and self-conscious emotions are no independent predictors for problem behavior. Age and sex however do independently and significantly contribute to the variation of problem behavior of youths.

Taken together, the results seem to indicate that youths who classify themselves as securely attached individuals would experience higher levels of self-conscious emotions than youths who grew up with insecurely attachment. Communication, one of the positive dimensions of attachment, was in fact positively correlated with various forms of shame and guilt. This means a higher degree of communication goes hand in hand with a greater tendency to experience self-conscious emotions, and vice versa. In other words, the hypothesis that insecure attachment is associated with a lower tendency to experience self-conscious emotions is partly confirmed in this study. In case the subscales without enough reliability are left out of account the hypothesis can be fully confirmed.

Furthermore, it was hypothesized that the negative dimension of attachment, alienation, as well a disruption of self-conscious emotions was accompanied by a greater extent of problem behavior. In the present study significant results were found that endorse this hypothesis. More trust in parents and peers was associated with respectively less problem behavior and less peer problems.

Moreover, the results showed that problem behavior is not only determined by the quality of the attachment relationship or the propensity to experience self-conscious emotions, but by a combination of these variables. More specifically, various combinations of attachment and self-conscious emotions have coherence with the total extent of difficulties. Attachment and self-conscious emotions therefore appeared to be no independent predictors for the overall level of problem behavior in youths. The regression analysis only showed a significant main effect of age and gender on problem behavior of youths.

It should be admitted that the present study suffered from various limitations. To begin with, the study was cross-sectional in nature, which means that no conclusions can be drawn in terms of cause-effect relationships. Future longitudinal research is necessary to explore whether attachment actually acts as a precursor of self-conscious emotions, as suggested by literature (Lewis, 1971). In addition, longitudinal research is needed to analyze whether attachment and self-conscious emotions have still possible influence on the development of problem behavior. Second, the study population must be taken 
into consideration. The present study is based on a small population $(N=31)$ causing the study has little power. In addition, the population consisted of young people who had been in contact with the Child Care and Protection Agency so the results cannot be generalized to the general population. Third, the measuring instruments are far from adequate in the present study. All three questionnaires - SCEMAS, IPPA and SDO - have reliability coefficients in the present study that are unacceptable (Field, 2013). Compared with previous research, the present study differs from previous studies. These deviations in reliability coefficients can possibly be attributed to the particular characteristics of the present study population. Previous studies have shown that adolescents who have been in contact with the Child Care and Protection Agency have different attitudes compared to the general population, which leads to different results (Feilhauer, Cima \& Arntz, 2012).

In spite of these drawbacks, the results of the present study were largely in keeping with the current models about the role of attachment and self-conscious emotions in the ethology of problem behavior. Current concepts suggest that early attachment experiences influence future behavior of an individual (Kochanska \& Kim, 2013; Sroufe, 2005; Zegers et al., 2008). In addition, the concepts indicate that attachment is involved in children's proneness to experience self-conscious emotions (Muris et al., 2014). Furthermore, a relationship has been demonstrated between self-conscious emotions, especially shame and guilt, and psychopathological symptoms (e.g. Gilbert \& Miles., 2000; Thompson \& Berenbaum, 2006). The expectations in the present study were based on these conceptualizations. Since the results in the present study were partially in accordance with what is documented so far concerning adolescents, the present study provides a valuable addition to the existing knowledge concerning the relationship between attachment, self-conscious emotions and problem behavior in adolescents.

\section{Role of the student}

Rachel Houtackers was an undergraduate student working under the supervision of Cor Meesters when the research in this report was performed. The topic was proposed by the supervisor. The analysis of the data and the processing of the results as well as formulation of the discussion and conclusion and the writing were done by the student. 


\section{References}

1. Ammaniti, M., Van IJzendoorn, M. H., Speranza, A. M., \& Tambelli, R. (2000). Internal working model of attachment during late childhood and early adolescence: an exploration of stability and change. Attachment \& Human Development, 2, 328-346.

2. Armsden, G.C., \& Greenberg, M.T. (1987). The Inventory of Parent and Peer Attachment: Individual differences and their relationship to psychological well-being in adolescence. Journal of Youth and Adolescence, 16, 427-454.

3. Aunola, K., \& Nurmi, J. (2005). The role of parenting styles in children's problem behavior. Child Development, 76, 1144-1159.

4. Bowlby, J. (1969). Attachment and loss. Volume I. New York: Basic Books.

5. Cooper, M. L., Shaver, P. R., \& Collins, N. L. (1998). Attachment styles, emotion regulation and adjustment in adolescence. Journal of Personality and Social Psychology, 74, 1380-1397.

6. Erickson, M. F., Sroufe, L. A., \& Egeland, B. (1985). The relationship between quality of attachment and behavior problems in preschool in a high-risk sample. Monographs of the Society for Research in Child Development, 50, 147-166.

7. Feilhauer, J., Cima, M., \& Arntz, A. (2012). Assessing callous-unemotional traits across different groups of youths: Further cross-cultural validation of the Inventory of Callous-Unemotional Traits. International Journal of Law and Psychiatry, 35, 251- 262.

8. Field, A. (2013). Discovering statistics using IBM SPSS statistics. Los Angeles: Sage.

9. Gilbert, P., \& Miles, J. N. (2000). Sensitivity to Social Put-Down: it's relationship to perceptions of social rank, shame, social anxiety, depression, anger and self-other blame. Personality and Individual Differences, 29, 757-774

10. Goodman, R. (1997). The Strengths and Difficulties Questionnaire: a research note. Journal of Child Psychology and Psychiatry, 38, 581-586.

11. Kochanska, G., \& Kim, S. (2013). Early attachment organization with both parents and future behavior problems: From infancy to middle childhood. Child Development, 84, 283- 296.

12. Leith, K. P., \& Baumeister, R. F. (1998). Empathy, shame, guilt, and narratives of interpersonal conflicts: Guilt-prone people are better at perspective taking. Journal of Personality, 66, 1-37

13. Lewis, H. B. (1971). Shame and guilt in neurosis. Psychoanalytic Review, 58, 419-438.

14. Lewis, M. (2008). Self-conscious emotions, embarrassment, pride, shame and guilt. In M. Lewis, J.M. Haviland-Jones, \& L. Feldman Barrett (Red.), Handbook of emotions (pp. 742-756). New York: The Guilford Press.

15. Meij, H. (2011). De basis van opvoeding en ontwikkeling. Utrecht: Nederlands Jeugdinstituut.

16. Muris, P., Meesters, C., \& van den Berg, F. (2003). The strengths and difficulties questionnaire (SDO). European Child \& Adolescent Psychiatry, 12, 1-8. 
17. Muris, P., \& Meesters, C. (2014). Small or big in the eyes of the other: on the developmental psychopathology of self-conscious emotions as shame, guilt, and pride. Clinical Child and Family Psychology Review, 17, 19-40.

18. Muris, P., Meesters, C., Cima, M., Verhagen, M., Brochard, N., Sanders, A., Kempener, C., Beurskens, J., \& Meesters, V. (2014). Bound to feel bad about oneself: relations between attachment and the selfconscious emotions of guilt and shame in children and adolescents. Journal of Child and Family Studies, $23,1278-1288$

19. Soenens, B., Vansteenkiste, M., Luyckx, K., \& Goossens, L. (2006). Parenting and adolescent problem behavior: an integrated model with adolescent self-disclosure and perceived parental knowledge as intervening variables. Developmental Psychology, 42, 305-318.

20. Sroufe, L. A. (2005). Attachment and development: A prospective, longitudinal study from birth to adulthood. Attachment and Human Development, 7, 349-367.

21. Stegge, H., \& Ferguson, T. J. (1990). Child-Child Attribution and Reaction Survey (C-CARS). Unpublished manuscript. Amsterdam: Free University and Logan, UT: Utah State University.

22. Stegge, H., \& Ferguson, T. J. (1994). Self-Conscious Emotions: Maladaptive and Adaptive Scales (SCEMAS). Unpublished manuscript. Amsterdam: Free University and Logan, UT: Utah State University.

23. Thompson, R. J., \& Berenbaum, H. (2006). Shame reactions to everyday dilemmas are associated with depressive disorder. Cognitive Therapy and Research, 30, 415-425.

24. Tracy, J. L., \& Robins, R. W. (2004). "Putting the Self Into Self-Conscious Emotions: A Theoretical Model”. Psychological Inquiry, 15, 103-125.

25. Zaal, S., Boerhave, M., \& Koster, M. (2009). Hechting basisveiligheid basisvertrouwen: begeleiding en behandeling. Amsterdam: Cordaan en Amsta.

26. Zegers, M. A., Schuengel, C., Van IJzendoorn, M. H., \& Janssens, J. M. (2008). Attachment and problem behavior of adolescents during residential treatment. Attachment \& Human Development, 10, 91-103. 